\title{
Comparative study of IDH1 mutations in gliomas by high resolution melting analysis, immunohistochemistry and direct DNA sequencing
}

\author{
JUAN LI ${ }^{1,2 *}$, HAIYAN ZHANG ${ }^{2 *}$, LI WANG $^{2}$, CHUANHONG YANG $^{2}$, \\ HUANGWEN LAI ${ }^{2}$, WEI ZHANG ${ }^{3}$, XIAODONG CHEN $^{3}$ and JIE WANG $^{2}$
}

${ }^{1}$ Department of Biochemistry and Molecular Biology, School of Bioscience and Bioengineering, South China University of Technology, Guangzhou, Guangdong 510006; Departments of ${ }^{2}$ Medical Research and ${ }^{3}$ Pathology, Guangzhou General Hospital of Guangzhou Military Command, Guangzhou, Guangdong 510010, P.R. China

Received August 27,2014; Accepted May 8, 2015

DOI: $10.3892 / \mathrm{mmr} .2015 .3987$

\begin{abstract}
Patients with glioblastomas with a specific mutation in the isocitrate dehydrogenase 1 (IDH1) gene have a better prognosis than those with gliomas with wild-type IDH1. IDH1 analysis has become part of the standard diagnostic procedure and a promising tool used for stratification in clinical trials. The present study aimed to compare high resolution melting (HRM) analysis, immunohistochemistry (IHC) and direct DNA sequencing for the detection of IDH mutations in gliomas. Fifty-one formalin-fixed paraffin-embedded tumor samples were selected. For the HRM analysis and direct DNA sequencing, DNA was extracted from the tissues. For IHC, sections were stained with an anti-IDH1-R132H specific antibody. The HRM analysis method identified 33 cases of IDH1 gene mutations, and all mutations occurred at the $\mathrm{R} 132 \mathrm{H}$ site. There were 33 cases of IDH1 gene mutations found by IHC, which was consistent with that identified using the HRM analysis method. However, only 30 IDH1 samples were confirmed by sequencing, in which mutations occurred at the IDH1 exon $4 \mathrm{R} 132 \mathrm{H}$ site. No mutation was detected in the other three of these 33 cases (two grade II oligodendroglioma and one grade II diffuse astrocytoma) by sequencing, while IHC was positive for IDH1-R132H. The results showed that the mutation detection rate was not identified to be significantly different $(\mathrm{P}=0.250)$ when determined by the HRM analysis
\end{abstract}

Correspondence to: Professor Jie Wang, Department of Medical Research, Guangzhou General Hospital of Guangzhou Military Command, 111 Liuhua Road, Guangzhou, Guangdong 510010, P.R. China

E-mail: jiew@tom.com

*Contributed equally

Key words: isocitrate dehydrogenase 1, mutation, high resolution melting, immunohistochemistry, direct DNA sequencing method or by direct DNA sequencing, as the concordant rate between the two methods was high $(\kappa=0.866)$. The HRM analysis method in glioma IDH1 gene mutation detection has advantages of high sensitivity, good repeatability, simple operation and accurate results. It provides a novel method for detecting mutations of the IDH1 gene in paraffin embedded tissue samples of clinical glioma. Related to a small amount of sample, there was no evidence showing that HRM analysis method is superior to IHC. Direct DNA sequencing, HRM analysis and IHC results were consistent; however, HRM and IHC are more sensitive than direct DNA sequencing in identifying the IDH1-R132H mutation.

\section{Introduction}

Malignant glioma is the most common type of human primary brain tumor. Mutations in the citric acid cycle enzyme isocitrate dehydrogenase 1 (IDH1) have recently been implicated in gliomagenesis. The IDH1 gene is located on chromosome 2q33.3, full-length $18,841 \mathrm{bp}$, including 10 exons and 9 introns, encoding isocitrate dehydrogenase, which is involved in the TCA cycle and catalyzes the oxidative decarboxylation of isocitrate to $\alpha$-ketoglutarate. In glioma, $>90 \%$ of IDH mutations occur in IDH1, and the majority of the IDH1 mutations $(\sim 90 \%)$ are arginine replaced by histidine (R132H) $(1,2)$. There are a few other types of mutations, such as R132C (3.6-4.6\%), R132G (0.6-3.8\%), R132S (0.8-2.5\%) and R132P (0.4\%) (3). Generally, the IDH1 mutation occurs in the World Health Organization (WHO) grade II-III gliomas and secondary glioblastomas (3). IDH1 mutations can change the structure of isocitrate dehydrogenase, resulting in a loss of its ability to convert isocitrate into ketoglutarate, and causing it to gain novel enzyme activity, converting $\alpha$ ketoglutaric acid into 2-hydroxyglutarate. Subsequent studies have shown that IDH1 mutations are an early step in gliomagenesis, before TP53 mutations or loss of 1p/19q occurs (4). Recent studies show that the IDH1 $(\mathrm{R} 132 \mathrm{H})$ overexpression decreases the proliferation of glioma cell lines, alters morphology, increases contact-dependent cell migration (5), and blocks the differentiation of non-transformed cells (6). 
Studies show that the IDH1 mutation status is strongly predictive of a better prognosis in secondary glioblastomas (7) as well as in anaplastic astrocytomas and oligodendrogliomas (8). Conversely, it has been shown that patients diagnosed with anaplastic astrocytomas without an IDH1 mutation have a worse prognosis than glioblastomamultiforme (GBM) patients with an IDH1 mutation (9), suggesting that these patients could benefit from treatment stratification by IDH mutation analysis. Therefore, the determination of the mutational status of IDH1 has become a part of the standard diagnostic procedure and a promising tool used for stratification in clinical trials as it is one of the major prognostic factors in glioma (10).

Currently, mutational detection is mostly based on direct DNA sequencing of polymerase chain reaction (PCR) products or quantitative PCR using allele specific probes, which can detect a high proportion of mutations. However, they require trained professionals and sophisticated equipment that is not available in all laboratories, and they are labor intensive. Moreover, inadequate tumor DNA availability may lead to false-negative results due to small tissue samples, extensive necrosis, contaminated tumor samples or admixture with normal tissue elements. Immunohistochemistry (IHC) is an easy and quick method for detecting IDH1-R132H mutations with high sensitivity and specificity, but it is not suitable for other types of mutations, including R132C, R132S, R132G, R132L, R132V and R132P, as IMab-1 and other DIA-H09 antibodies are only able to detect the IDH1-R132H mutation (11,12). Antibodies specific for mutations other than $\mathrm{R} 132 \mathrm{H}$ have also been developed (13-15); however, their efficiency requires further validation in the clinic. HRM analysis is a post-PCR method that provides rapid identification of nucleotide variation, based on biophysical measurement of the amplified DNA. This technique can be performed in any laboratory with a suitable real-time PCR thermocycler, which provides considerably decreased time and cost compared with other screening methods. This methodology is faster, simpler and has a superior sensitivity and specificity compared with other screening techniques, and has been implemented for mutation screening and clinical diagnosis in numerous different genetic diseases $(16,17)$.

The present study aimed to compare HRM analysis, IHC and DNA sequencing for the detection of IDH mutations in 51 formalin-fixed paraffin-embedded tissue specimens of gliomas obtained from Guangzhou General Hospital of Guangzhou Military Command (Guangzhou, China).

\section{Materials and methods}

Tumor specimens and DNA preparation. A total of 51 patients with glioma who were diagnosed and treated at the Guangzhou General Hospital of Guangzhou Military Command between August 2009 and August 2013, were selected for the present study. Formalin-fixed and paraffin-embedded tumor samples were obtained from the General Hospital of Guangzhou Military Command. All experiments using the human samples were approved by the ethical committee of Guangzhou General Hospital of Guangzhou Military Command. All tumors were classified according to the WHO classification of tumors of the central nervous system. There were 8 cases of diffuse astrocytoma (WHO grade II), 2 anaplastic astocytoma (WHO grade III), 20 GBMs (WHO grade IV), 9 oligodendroglioma
(OG) (WHO grade II), 6 OG (WHO grade III) and 6 oligoastrocytoma (WHO grade II). Sections were stained with hematoxylin and eosin (H\&E) to confirm that diagnostic tissue morphology had been retained.

Paraffin embedded tissue specimens were cut into 5- $\mu \mathrm{m}$ sections and used for DNA extraction, and then subsequent $3-\mu \mathrm{m}$ sections were stained with $\mathrm{H} \& \mathrm{E}$ and IHC was conducted. DNA from the tumor tissue was extracted using the DNA QIAamp kit (cat. no. 56404, Qiagen GmbH, Hilden, Germany) according to the manufacturer's instructions. The quantity of isolated genomic DNA was evaluated using a NanoDrop 2000 spectrophotometer (Thermo Scientific, Wilmington, DE, USA). The ratio of the absorbance at 260 and $280 \mathrm{~nm}$ was between 1.8 and 2.0. Sections were stained with H\&E staining to confirm that diagnostic tissue has been retained.

HRM analysis of IDHI mutations. The DNA concentration was adjusted to $30 \mathrm{ng} / \mu \mathrm{l}$ and IDH1 mutations were detected by HRM analysis (Rotor-Gene 6000 Analyzer, Qiagen $\mathrm{GmbH}$ ). The primer sequences used were as follows: Forward: 5'-CGGTCTTCAGAGAAGCCATT-3' and reverse: 5'-GCAAAATCACATTATTGCCAAAC-3'. HRM amplification was performed in a $20 \mu 1$ reaction mixture for IDH1 containing 2.0 $\mu \mathrm{l}$ DNA, $0.6 \mu \mathrm{l}$ of each forward $(10 \mu \mathrm{mol} / \mathrm{l})$ and reverse primer (10 $\mu \mathrm{mol} / \mathrm{l}), 6.3 \mu \mathrm{l}$ RNase-free water, $0.5 \mu 1 \mathrm{Mg}^{2+}(25 \mathrm{mM})$ and $10 \mu \mathrm{l}$ of $2 \mathrm{X}$ HRM PCR Master Mix buffer (cat. no. 206542, Qiagen $\mathrm{GmbH}$ ). Predenaturation was performed at $94^{\circ} \mathrm{C}$ for $10 \mathrm{~min}$. This was followed by 50 cycles of amplification consisting of denaturation at $95^{\circ} \mathrm{C}$ for $20 \mathrm{sec}$, annealing at $53^{\circ} \mathrm{C}$ for $20 \mathrm{sec}$, and extension at $72^{\circ} \mathrm{C}$ for $20 \mathrm{sec}$. HRM is based on computer analysis of DNA melting transitions. Post-amplification HRM was performed by gradual heating of the samples at a rate of $0.1^{\circ} \mathrm{C} / \mathrm{sec}$ from $65^{\circ} \mathrm{C}$ to $95^{\circ} \mathrm{C}$, via monitoring the changes in fluorescence that result from gradual temperature-dependent release of a saturating dsDNA binding dye.

Direct DNA sequencing of IDH1 mutations. Mutations in exon 4 of the IDH1 gene were also determined by direct DNA sequencing in all cases. The primer sequences used were as follows: Forward: 5'-CGGTCTTCAGAGAAGCCATT-3' and reverse: 5'-GCAAAATCACATTATTGCCAAAC-3'. For IDH1 mutation detection, PCR amplification was performed in a total $20 \mu \mathrm{l}$ reaction mixture containing $1.5 \mu \mathrm{l}$ DNA, $0.5 \mu \mathrm{l}$ of each forward and reverse primers, 7.5 $\mu \mathrm{l}$ RNase-free water and $10 \mu \mathrm{l}$ of 2X HRM PCR Master Mix buffer. Predenaturation was performed at $95^{\circ} \mathrm{C}$ for $10 \mathrm{~min}$. This was followed by 50 cycles of amplification consisting of denaturation at $95^{\circ} \mathrm{C}$ for $20 \mathrm{sec}$, annealing at $54^{\circ} \mathrm{C}$ for $20 \mathrm{sec}$, and extension at $72^{\circ} \mathrm{C}$ for $20 \mathrm{sec}$. When amplification was complete, PCR products were sent to Shenzhen BGI (Shenzhen, China) for direct DNA sequencing.

IHC analysis of IDHI mutations. IHC staining for IDH1-R132H was performed with mouse anti-human IDH1-R132H monoclonal antibody (MAB-0662; Maixin Bio, Fuzhou, China), which reacts specifically with IDH1-R132H mutant protein. ElivisionTM plus Polyer horseradish peroxidase (mouse/rabbit) (KIT-9901; Maixin Bio) IHC kit, DAB Detection kit (Maixin Bio) were used as a detection 
Table I. Details of the cases included in the study.

\begin{tabular}{|c|c|c|c|c|c|c|}
\hline No. & Gender & Age (years) & Diagnosis & $\begin{array}{l}\text { IHC for } \\
\text { IDH1 }\end{array}$ & $\begin{array}{l}\text { IDH1 mutation on } \\
\text { initial DNA sequencing }\end{array}$ & $\begin{array}{l}\text { IDH1 mutation } \\
\text { with HRM }\end{array}$ \\
\hline 1 & M & 51 & OGII & + & + & + \\
\hline 2 & M & 65 & OGII & + & + & + \\
\hline 3 & $\mathrm{~F}$ & 26 & OGII & - & - & - \\
\hline 4 & $\mathrm{~F}$ & 44 & OGII & - & - & - \\
\hline 5 & M & 22 & OGII & + & + & + \\
\hline 6 & $\mathrm{~F}$ & 36 & OGII & + & - & + \\
\hline 7 & $\mathrm{~F}$ & 22 & OGII & + & - & + \\
\hline 8 & $\mathrm{~F}$ & 44 & OGII & - & - & - \\
\hline 9 & $\mathrm{~F}$ & 61 & OGII & + & + & + \\
\hline 10 & M & 46 & OGIII & + & - & + \\
\hline 11 & M & 21 & OGIII & + & + & + \\
\hline 12 & M & 15 & OGIII & - & - & - \\
\hline 13 & M & 35 & OGIII & + & + & + \\
\hline 14 & M & 51 & OGIII & + & + & + \\
\hline 15 & M & 55 & OGIII & + & + & + \\
\hline 16 & M & 34 & OAII & + & + & + \\
\hline 17 & M & 47 & OAII & - & - & - \\
\hline 18 & $\mathrm{~F}$ & 10 & OAII & + & + & + \\
\hline 19 & M & 57 & OAII & + & + & + \\
\hline 20 & $\mathrm{~F}$ & 41 & OAII & + & + & + \\
\hline 21 & M & 35 & OAII & + & + & + \\
\hline 22 & M & 57 & DAII & - & - & - \\
\hline 23 & M & 45 & DAII & + & - & + \\
\hline 24 & $\mathrm{~F}$ & 35 & DAII & - & - & - \\
\hline 25 & $\mathrm{~F}$ & 54 & DAII & + & + & + \\
\hline 26 & $\mathrm{~F}$ & 29 & DAII & - & - & - \\
\hline 27 & M & 48 & DAII & + & + & + \\
\hline 28 & M & 36 & DAII & - & - & - \\
\hline 29 & M & 12 & DAII & + & + & + \\
\hline 30 & M & 12 & AAIII & + & + & + \\
\hline 31 & M & 33 & AAIII & + & + & + \\
\hline 32 & $\mathrm{~F}$ & 22 & Pri GBM & - & - & - \\
\hline 33 & $\mathrm{~F}$ & 40 & Pri GBM & - & - & - \\
\hline 34 & M & 42 & Pri GBM & - & - & - \\
\hline 35 & $\mathrm{~F}$ & 19 & Pri GBM & - & - & - \\
\hline 36 & M & 16 & Pri GBM & - & - & - \\
\hline 37 & $\mathrm{~F}$ & 28 & Pri GBM & - & - & - \\
\hline 38 & M & 42 & Pri GBM & - & - & - \\
\hline 39 & M & 28 & Pri GBM & - & - & - \\
\hline 40 & M & 18 & Pri GBM & - & - & - \\
\hline 41 & M & 53 & Sec GBM & + & + & + \\
\hline 42 & M & 65 & Sec GBM & + & + & + \\
\hline 43 & M & 44 & Sec GBM & + & + & + \\
\hline 44 & $\mathrm{~F}$ & 35 & Sec GBM & + & + & + \\
\hline 45 & $\mathrm{~F}$ & 37 & Sec GBM & + & + & + \\
\hline 46 & $\mathrm{~F}$ & 36 & Sec GBM & + & + & + \\
\hline 47 & M & 38 & Sec GBM & + & + & + \\
\hline 48 & $\mathrm{~F}$ & 51 & Sec GBM & + & + & + \\
\hline 49 & $\mathrm{~F}$ & 44 & Sec GBM & + & + & + \\
\hline 50 & M & 47 & Sec GBM & + & + & + \\
\hline 51 & M & 37 & Sec GBM & + & + & + \\
\hline
\end{tabular}

IHC, immunohistochemistry; HRM, high resolution melting analysis; IDH1, isocitrate dehydrogenase 1; M, male; F, female; OG, oligodendroglioma; OA, oligoastrocytoma; DA, diffuse astrocytoma; AA, anaplastic astrocytoma; GBM, glioblastomamultiforme; Pri, primary; Sec, secondary; +, positive; -, negative. 


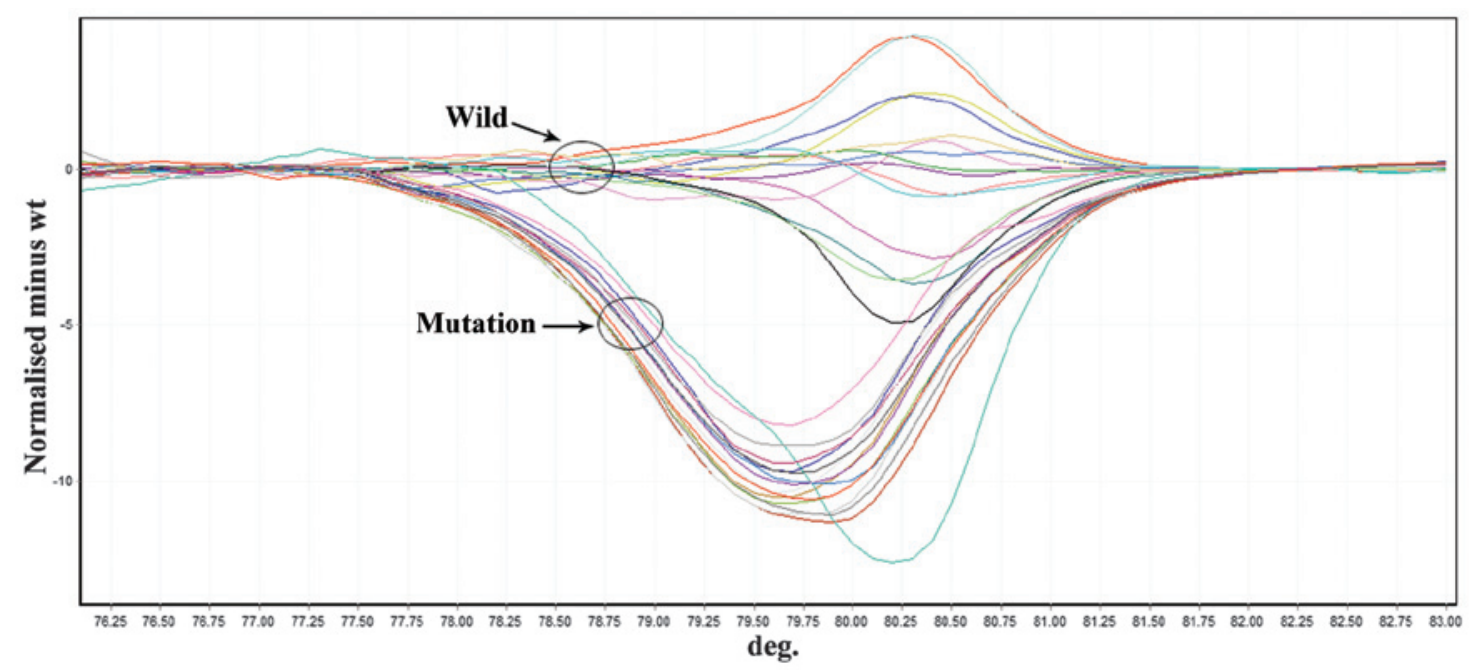

Figure 1. HRM analysis of the IDH1 gene in gliomas. Fluorescence melting peaks were built by plotting the negative derivative of fluorescent signal corresponding to the temperature, mutations cause different melting properties; thus, homozygous mutants can be distinguished from wt amplicons according to subtle Tm shift. HRM, high resolution melting; IDH1, isocitrate dehydrogenase 1; wt, wild-type.
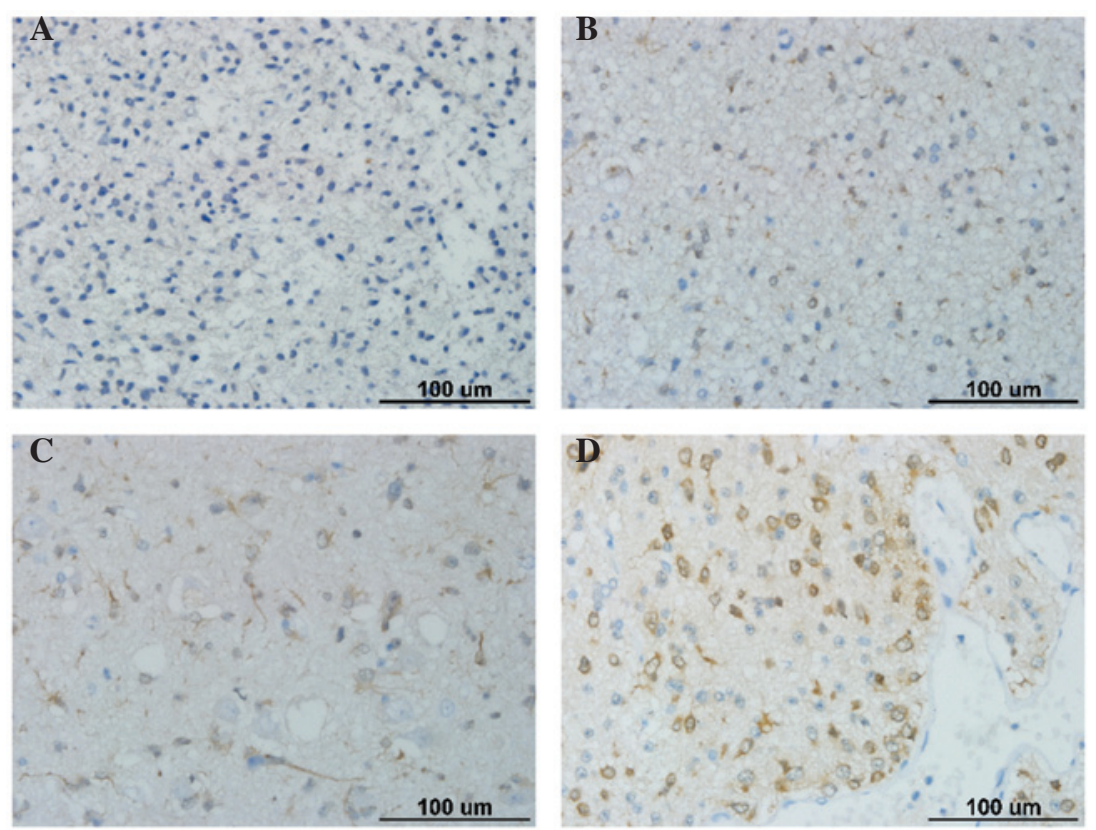

Figure 2. Immunohistochemistry analysis of isocitrate dehydrogenase 1. (A) Negative; (B) oligodendroglioma grade II; (C) oligodendroglioma grade II; and (D) diffuse astrocytoma grade II.

system. The IHC staining was performed according to the manufacturer's instructions. For glioma cells, staining in the cytoplasm of neoplastic cells was regarded as positive, while for normal brain, only staining in the cytoplasm of astrocytes and oligodendrocytes was regarded as positive. The result of IHC was determined by a semiquantitative method; the proportion of positively stained tumor cells was rated as follows: Cases with $>10 \%$ stained cells were rated as positive, and cases with $<10 \%$ stained cells were rated as negative.

Statistical analysis. Statistical analyses were performed using the Statistical Package for the Social Sciences version 13.0 (SPSS Inc., Chicago, IL, USA). McNemar test was used to compare direct sequencing and HRM results, and the concordant rate between the two methods were assessed by Kappa test. $\mathrm{P}<0.05$ was considered to indicate a statistically significant difference.

\section{Results}

HRM analysis method. Out of the 51 cases, 33 IDH1 gene mutations were identified, as determined by HRM analysis (Tables I and II). All of the identified mutations were $\mathrm{R} 132 \mathrm{H}$, and the rest were wild type (Fig. 1).

IHC analysis. IHC results were determined by a semiquantitative method, and there were 33 cases of IDH1 gene mutations identified, which was consistent with those identified by 
Table II. Results of IDH1 mutation by IHC analysis, direct DNA sequencing and HRM analysis method (total number=51).

\begin{tabular}{lccc}
\hline IDH1 & IHC & $\begin{array}{c}\text { HRM analysis } \\
\text { method }\end{array}$ & $\begin{array}{c}\text { Direct DNA } \\
\text { sequencing }\end{array}$ \\
\hline Mutation & 33 & 33 & 30 \\
Wild & 18 & 18 & 21
\end{tabular}

IHC result was consistent with HRM. Comparison of IDH1 between DNA sequencing and HRM analysis method, McNemar; $\mathrm{P}=0.250$ ( $\mathrm{P}>0.05)$; $\kappa=0.874(\kappa>0.7)$. IDH1, isocitrate dehydrogenase 1 ; ICH, immunohistochemistry; HRM, high resolution melting.

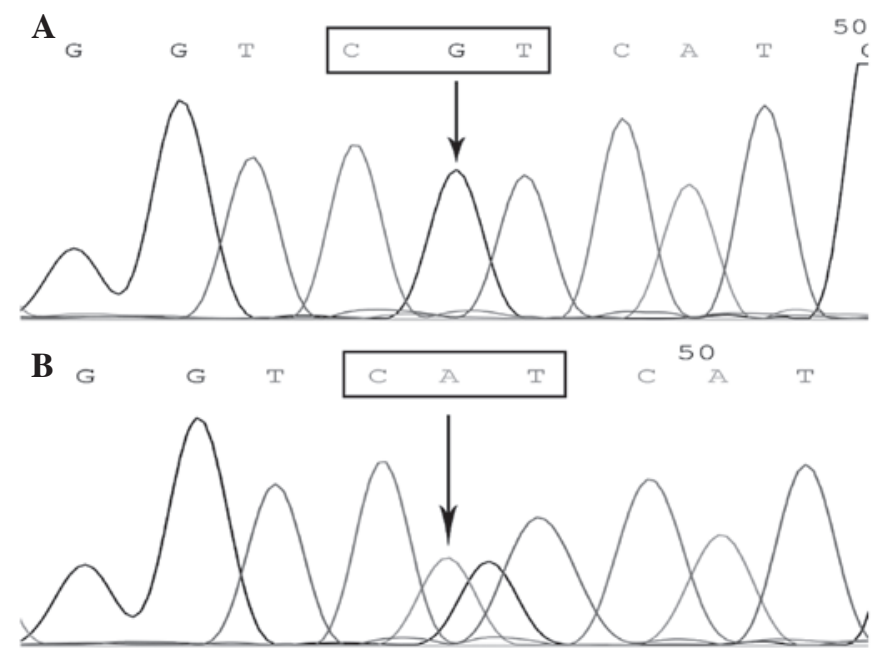

Figure 3. Sequencing results of IDH1 mutations and wild-type samples. (A) wild-type; (B) IDH1 R132H mutation as CGT is changed to CAT. IDH1, isocitrate dehydrogenase.

HRM. Immunolocalization of IDH1-R132H detected by anti-IDH1-R132H antibodies in human gliomas is shown in Fig. 2.

Direct DNA Sequencing. There were 30 IDH1 gene mutation samples confirmed by direct DNA sequencing, which all exhibited mutations in the IDH1 exon 4 R132H site (Fig. 3). However, in three cases (two grade II oligodendroglioma and one grade II diffuse astrocytoma), direct DNA sequencing failed to reveal any mutation, whereas IHC was positive for the IDH1-R132H mutation. These results indicate that there is no significant difference in the identification of mutations $(\mathrm{P}>0.05)$ between HRM and direct DNA sequencing, and the concordant rate between the two methods was high $(\kappa=0.866)$.

\section{Discussion}

Mutations in the IDH1 genes have been identified in a large proportion of diffuse gliomas (18). IDH1 mutations are regarded as one of the most significant genetic alterations in gliomagenesis, based on the mutation profiles of various subtypes of gliomas as well as primary and recurrent tumors $(3,19)$.
A high percentage of grade II and III gliomas have mutations in the gene encoding IDH1. This mutation is always a heterozygous point mutation that affects the amino acid arginine at position 132 and results in loss of its native enzymatic activity and increase of alternative enzymatic activity (producing D-2-hydroxyglutarate). Rational IDH1 mutation analysis is beneficial for differential diagnosis as well as providing prognostic information. Patients with known IDH1 mutations may also benefit from targeted chemotherapy regimens utilizing novel inhibitors of mutated IDH1, which are currently in development. Mutations of the IDH1 gene have been proposed to exhibit a significant role in the tumorigenesis, progression and prognosis of gliomas.

In a comparative study between IHC and genetic testing, Capper et al (20) found that IHC was 100\% sensitive and specific in detecting IDH1-R132H mutations, suggesting that anti-IDH1-R132H immunostaining is a reliable method for the evaluation of IDH1 gene mutation status. In a study by Agarwal et al (21), 50 diffuse gliomas with frozen tissue samples for DNA sequencing and adequate tissue in paraffin blocks for IHC using IDH1-R132H specific antibodies were analyzed for IDH1 mutations. Concordance between IHC and DNA sequencing was noted in 88\% (44/50) of cases (22). Through comparing antibody and sequencing methods for the detection of IDH mutations, Kurian et al (23) suggested that the detection of IDH1 mutations using antibodies is cheaper than sequencing; however, sequencing demonstrates rare IDH1 mutations that cannot been detected by IHC. Takano et al (24) used IMab-1 detected the mutation in 12 out of 49 cases of human glioma samples; however, only nine cases were identified as IDH1-R132H by direct DNA sequencing due to the small population of IDH1-R132H mutation-possessing tumor cells, indicating that IHC is useful for detecting IDH1-R132H mutations (24).

With the increasing identification of recurrent mutations in cancer, the development of fast and efficient approaches for mutational screening is required. An alternative technique for mutation detection is HRM analysis (25). HRM analysis is a fast single-well-technique combining PCR using saturating fluorescent dsDNA binding dye and melt curve analysis. Fluorescence melting peaks are built by plotting the negative derivative of fluorescent signals corresponding to the temperature. As mutations cause different melting properties, homozygous mutants can be distinguished from wild-type amplicons according to subtle Tm shifts. Lin et al (26) evaluated the sensitivity of HRM in the detection of the IDH1 R132 mutation and screened IDH1 mutations in 110 patients with acute myeloid leukemia using HRM analysis, and observed that the reproducible sensitivity of HRM was 5\% for the detection of IDH1 R132 mutation, which is higher than that of direct DNA sequencing $(10 \%)(26)$.

In the present study, real-time PCR, combined with saturated fluorescent dyes and HRM analysis software, was used to detect IDH1 gene mutations in gliomas. The HRM analysis method identified 33 cases of IDH1 gene mutations, and all mutations occurred at the $\mathrm{R} 132 \mathrm{H}$ site. There were 33 cases of IDH1 gene mutations found by the IHC method, which was consistent with the HRM analysis method. Only 30 IDH1 samples were confirmed by direct DNA sequencing, in which mutations occurred at the IDH1 exon 4 R132H site (Fig. 3). In 
the other 3 of these 33 cases, two grade II oligodendroglioma and one grade II diffuse astrocytoma, direct DNA sequencing failed to reveal any mutations while IHC was positive for the IDH1-R132H mutation using the anti-IDH1-R132H antibody. The reason leading to this discrepancy may be the small number of tumor cells in these 3 samples, or that tumor samples were contaminated. This indicates that the anti-IDH1-R132H antibody is more sensitive than direct DNA sequencing; a result that was concurrent with those of, and the result was similar with Takano et al (27). Results showed that the rate of IDH1 gene mutation detection in gliomas was not significantly different $(\mathrm{P}=0.250)$ between HRM analysis and direct DNA sequencing, as the concordance rate between the two methods was high $(\kappa=0.866)$. The results of direct DNA sequencing, HRM analysis and IHC in detecting IDH1 gene mutations in gliomas are consistent, however HRM analysis and IHC are more sensitive than direct DNA sequencing in identifying the IDH1-R132H mutation.

In conclusion, HRM analysis in glioma IDH1 gene mutation detection exhibits advantages of high sensitivity, good repeatability, simple operation and accurate results. It provides a novel method for clinical glioma in paraffin embedded tissue samples to detect the mutations in the IDH1 gene. Related to a small amount of sample, there was no evidence showing that HRM analysis is better than IHC. However, HRM analysis may be superior to IHC in the detection of unknown mutations, and this need a large number of clinical specimens to concern.

\section{References}

1. Hartmann C, Meyer J, Balss J, Capper D, Mueller W, Christians A, Felsberg J, Wolter M, Mawrin C, Wick W, et al: Type and frequency of IDH1 and IDH2 mutations are related to astrocytic and oligodendroglial differentiation and age: A study of 1010 diffuse gliomas. Acta Neuropathol 118: 469-474, 2009.

2. Gravendeel LA, Kloosterhoof NK, Bralten LB, van Marion R, Dubbink HJ, Dinjens W, Bleeker FE, Hoogenraad CC, Michiels E, Kros JM, et al: Segregation of non-p.R132H mutations in IDH1 in distinct molecular subtypes of glioma. Hum Mutat 31 E1186-E1199, 2010.

3. Yan H, Parsons DW, Jin G, McLendon R, Rasheed BA, Yuan W, Kos I, Batinic-Haberle I, Jones S, Riggins GJ, et al: IDH1 and IDH2 mutations in gliomas. N Engl J Med 360: 765-773, 2009.

4. Watanabe T, Nobusawa S, Kleihues P and Ohgaki H: IDH1 mutations are early events in the development of astrocytomas and oligodendrogliomas. Am J Pathol 174: 1149-1153, 2009.

5. Bralten LB, Kloosterhof NK, Balvers R, Sacchetti A, Lapre L, Lamfers M, Leenstra S, de Jonge H, Kros JM, Jansen EE, et al: IDH1 R132H decreases proliferation of glioma cell lines in vitro and in vivo. Ann Neurol 69: 455-463, 2011.

6. Lu C, Ward PS, Kapoor GS, Rohle D, Turcan S, Abdel-Wahab O, Edwards CR, Khanin R, Figueroa ME, Melnick A, et al: IDH mutation impairs histone demethylation and results in a block to cell differentiation. Nature 483: 474-478, 2012.

7. Nobusawa S, Watanabe T, Kleihues P and Ohgaki H: IDH1 mutations as molecular signature and predictive value of secondary glioblastomas. Clin Cancer Res 15: 6002-6007, 2009.

8. Sanson M, Marie Y, Paris S, Idbaih A, Laffaire J, Ducray F, El Hallani S, Boisselier B, Mokhtari K, Hoang-Xuan K, et al: Isocitrate dehydrogenase 1 codon 132 mutation is an important prognostic biomarker in gliomas. J Clin Oncol 27: 4150-4154, 2009 .
9. Hartmann C, Hentschel B, Wick W, Capper D, Felsberg J, Simon M, Westphal M, Schackert G, Meyermann R, Pietsch T, et al: Patients with IDH1 wild type anaplastic astrocytomas exhibit worse prognosis than IDH1-mutated glioblastomas and IDH1 mutation status accounts for the unfavourable prognostic effect of higher age: Implications for classification of gliomas. Acta Neuropathol 120: 707-718, 2010.

10. Van den Bent MJ, Hartmann C, Preusser M, Ströbel T, Dubbink HJ, Kros JM, von Deimling A, Boisselier B, Sanson M, Halling $\mathrm{KC}$, et al: Interlaboratory comparison of IDH mutation detection. J Neurooncol 112: 173-178, 2013.

11. Capper D, Zentgraf H, Balss J, Hartmann C and von Deimling A: Monoclonal antibody specific for IDH1 R132H mutation. Acta Neuropathol 118: 599-601, 2009.

12. Kato Y, Jin G, Kuan CT, McLendon RE, Yan H and Bigner DD: A monoclonal antibody IMab-1 specifically recognizes IDH1 $\mathrm{R} 132 \mathrm{H}$, the most common glioma-derived mutation. Biochem Biophys Res Commun 390: 547-551, 2009.

13. Kaneko MK, Tian W, Takano S, Suzuki H, Sawa Y, Hozumi Y, Goto K, Yamazaki K, Kitanaka C and Kato Y: Establishment of a novel monoclonal antibody SMab-1 specific for IDH1-R132S mutation. Biochem Biophys Res Commun 406: 608-613, 2011.

14. Kaneko MK, Morita S, Tsujimoto Y, Yanagiya R, Nasu K, Sasaki H, Hozumi Y, Goto K, Natsume A, Watanabe M, et al: Establishment of novel monoclonal antibodies KMab-1 and MMab-1 specific for IDH2 mutations. Biochem Biophys Res Commun 432: 40-45, 2013.

15. Kato Y, Natsume A and Kaneko MK: A novel monoclonal antibody GMab-m1 specifically recognizes IDH1-R132G mutation. Biochem Biophys Res Commun 432: 564-567, 2013.

16. Cui G, Ding H, Xu Y, Li B and Wang DW: Applications of the method of high resolution melting analysis for diagnosis of Leber's disease and the three primary mutation spectrum of LHON in the Han Chinese population. Gene 108-112, 2013.

17. Harle A, Lion M, Lozano N, Husson M, Harter V, Genin P and Merlin JL: Analysis of PIK3CA exon 9 and 20 mutations in breast cancers using PCR-HRM and PCR-ARMS: Correlation with clinicopathological criteria. Oncol Rep 29: 1043-1052, 2013.

18. Parsons DW, Jones S, Zhang X, Lin JC, Leary RJ, Angenendt P, Mankoo P, Carter H, Siu IM, Gallia GL, et al: An integrated genomic analysis of human glioblastoma multiforme. Science 321: 1807-1812, 2008.

19. Johnson BE, Mazor T, Hong C, Barnes M, Aihara K, McLean CY, Fouse SD, Yamamoto S, Ueda H, Tatsuno K, et al: Mutational analysis reveals the origin and therapy-driven evolution of recurrent glioma. Science 343: 189-193, 2014.

20. Capper D, Weissert S, Balss J, Habel A, Meyer J, Jäger D, Ackermann U, Tessmer C, Korshunov A, Zentgraf $\mathrm{H}$, et al: Characterization of R132H mutation-specific IDH1 antibody binding in brain tumors. Brain Pathol 20: 245-254, 2010.

21. Agarwal S, Sharma MC, Jha P, Pathak P, Suri V, Sarkar C, Chosdol K, Suri A, Kale SS, Mahapatra AK and Jha P: Comparative study of IDH1 mutations in gliomas by immunohistochemistry and DNA sequencing, Neuro Oncol 15: 718-726, 2013.

22. Agarwal S, Sharma MC, Jha P, Pathak P, Suri V, Sarkar C, Chosdol K, Suri A, Kale SS, Mahapatra AK, et al: Comparative study of IDH1 mutations in gliomas by immunohistochemistry and DNA sequencing. Neuro Oncol 15: 718-726, 2013.

23. Kurian KM, Haynes HR, Crosby C, Hopkins K and Williams M: IDH mutation analysis in gliomas as a diagnostic and prognostic biomarker. Br J Neurosurg 27: 442-445, 2013.

24. Takano S, Tian W, Matsuda M, Yamamoto T, Ishikawa E, Kaneko MK, Yamazaki K, Kato Y and Matsumura A: Detection of IDH1 mutation in human gliomas: Comparison of immunohistochemistry and sequencing. Brain Tumor Pathol 28: 115-123, 2011.

25. Wittwer CT: High-resolution DNA melting analysis: Advancements and limitations. Hum Mutat 30: 857-859, 2009.

26. Lin J, Qian J, Yao DM, Li Y, Yang J, Chen Q, Chai HY, Xiao GF and Xu WR: Rapid and reliable detection of IDH1 R132 mutations in acute myeloid leukemia using high-resolution melting curve analysis. Clin Biochem 44: 779-783, 2011.

27. Takano S, Tian W, Matsuda M, Yamamoto T, Ishikawa E, Kaneko MK, Yamazaki K, Kato Y and Masumura A: Detection of IDH1 mutation in human gliomas: Comparison of immunohistochemistry and sequencing. Brain Tumor Pathol 28: 115-123, 2011. 